\title{
Verapamil Inhibits the Glucose Transport Activity of GLUT1
}

\author{
Larry L. Louters • Nathan Stehouwer • \\ Janelle Rekman • Andrew Tidball • Alexandra Cok • \\ Christopher P. Holstege
}

Published online: 31 March 2010

(C) American College of Medical Toxicology 2010

\begin{abstract}
Calcium channel blocker toxicity has been associated with marked hyperglycemia responsive only to high-dose insulin therapy. The exact mechanism(s) of this induced hyperglycemia has not been clearly delineated. The glucose transporter GLUT1 is expressed in a wide variety of cell types and is largely responsible for a basal level of glucose transport. GLUT1 also is activated by cell stress. The specific purpose of this study was to investigate the effects of the calcium channel blocker verapamil on the glucose uptake activity of GLUT1 in L929 fibroblasts cells. Dose-dependent effects of verapamil on glucose uptake were studied using L929 fibroblast cells with 2-deoxyglucose. Verapamil had a dose-dependent inhibitory effect on both basal and stressactivated transport activity of GLUT1. Basal activity was inhibited $50 \%$ by $300 \mu \mathrm{M}$ verapamil, while $150 \mu \mathrm{M}$ verapamil completely inhibited the activation induced by the stress of glucose deprivation. These effects were reversible and required verapamil to be present during the stress. Alteration of calcium concentrations by addition of $5 \mathrm{mM} \mathrm{CaCl}_{2}$ or $4 \mathrm{mM}$ EDTA had no effect on verapamil action. This study reveals the unique finding that verapamil has inhibitory effects on the transport activity of GLUT1 independent of its effects on calcium
\end{abstract}

This research was supported by a grant from the University of Virginia, Department of Emergency Medicine Research Fund.

L. L. Louters · N. Stehouwer · J. Rekman · A. Tidball · A. Cok Department of Chemistry \& Biochemistry, Calvin College, Grand Rapids, MI, USA

C. P. Holstege ( $\square)$

Division of Medical Toxicology, Department of Emergency

Medicine, University of Virginia School of Medicine,

P. O. Box 800774, Charlottesville, VA 22908-0774, USA

e-mail: ch2xf@virginia.edu concentrations. The inhibition of GLUT1 may be one of the contributing factors to the hyperglycemia observed in $\mathrm{CCB}$ poisoning.

Keywords Calcium channel blocker Toxicity - GLUT1 . Insulin

\section{Introduction}

The incidence of calcium channel blocker (CCB) poisoning and related deaths has been steadily increasing over the past decade $[1,2]$. The effects of CCBs at toxic doses are largely ascribed to four mechanisms: (1) inhibition of calcium influx through L-type calcium channels, (2) inhibition of myocardial fast sodium channels, (3) inhibition of insulin release from pancreatic islet cells producing hypoinsulemia and hyperglycemia, and (4) inhibition of glucose uptake in peripheral tissues [3-9]. The CCB-induced decreased contractility can generate a shock state with an accompanying reduction in cell perfusion. Of particular importance is that this reduction of oxygen delivery triggers myocardial cells to switch from free fatty acids, the major fuel at normal aerobic conditions, to glucose [10]. The switch to glucose in cardiac cells occurs as both insulin release and peripheral insulin sensitivity is compromised [5, 7, 10-12]. Thus, glucose uptake is inhibited precisely as the cardiac cells need for glucose increases. This combination can contribute to the clinical effects described in the literature during $\mathrm{CCB}$ toxicity [5].

The hyperglycemia that frequently accompanies CCB poisoning is a strong indicator of the severity of the toxicity [13]. Often, the hyperglycemia cannot be resolved by physiological infusions of insulin, but requires high-dose insulin therapy (HDIT) [6]. Based on positive data from 
both animals and human case studies, HDIT (with or without concomitant infusions of glucose) is now gaining acceptance as an effective treatment strategy for CCB overdoses [11, 14-16]. However, there are few studies that document the extent of the CCB-dependent glucose uptake inhibition or that identify the molecular mechanisms responsible. Based on the limited available experimental evidence, the 2005 American Heart Association guidelines pertaining to emergency cardiovascular care list the use of glucose/insulin infusion in CCB toxicity as class indeterminate [17, 18]. Thus, a clearer understanding of the mechanism for the CCB-inhibited glucose uptake will support evidence-based HDIT and may help to further delineate treatment strategies for $\mathrm{CCB}$ toxicity.

The CCB-induced hyperglycemia suggests that high concentrations of CCBs compromise peripheral glucose uptake. A family of passive transporters known as the GLUTs mediates glucose uptake in mammalian system. There are 13 members of this family and cells often express more than on type of GLUT [19]. Two members of this family have received wide research attention: GLUT4, which is the insulin-regulated transporter that is found largely in muscle and fat tissue, and GLUT1, which has ubiquitous distribution, but is uniquely responsible for glucose transport into erythrocytes and across the blood brain barrier. Both of these transporters are subjected to acute regulation. For GLUT4, it has been well established that both exercise and insulin stimulate glucose uptake by an enhanced translocation of GLUT4 from internal stores to the cell surface membrane. GLUT1, on the other hand, is generally not sensitive to insulin or exercise, but can be activated within minutes by cell stressors such as hypoxia, hypoosmolarity, respiratory inhibitors, and glucose deprivation [20-25]. The mechanism of this activation is not well understood, but it is clear that it is not caused by a translocation of GLUT1 to the surface [20, 22].

The effects of CCBs, particularly verapamil, on the glucose transport activity of the GLUTs have been investigated. A CCB-dependent inhibition of glucose uptake has been documented in adipocytes [3, 26, 27], striated muscle [28], cardiac, and neuronal cells [29]. The cells or tissues used in these studies expressed more than one type of GLUT, and thus, the inhibitory activity was typically attributed to an effect on the most abundant transporter (GLUT4 for the insulin-sensitive cells). However, muscle tissue contains both GLUT1 and GLUT4 transporters with GLUT1 accounting for $25-40 \%$ of glucose transport under basal (non-insulin) conditions [30, 31]. Given the apparent insulin resistant state induced by CCBs and their inhibition of GLUT4 translocation [28], the importance of GLUT1 activity in CCB toxicity cases would likely be enhanced. The effects of CCBs on GLUT1 have not been fully described. Therefore, the purpose of this investigation was to determine the effects of verapamil on glucose uptake in L929 fibroblast cells, cells that only contain GLUT1 transporters [32]. Thus, any change in glucose uptake in this cell line can clearly be assigned to effects on GLUT1. Specifically, we measured the effects of verapamil on both the normal transport activity of GLUT1 and on the ability to activated GLUT1 by cell stress (glucose deprivation). In addition, since verapamil is a calcium channel blocker, we wanted to determine if these effects were dependent on changing calcium concentrations.

\section{Methods}

Each experiment reported in this study was done with L929 fibroblast cells in a 24-well plate. Experiments were repeated several times, and results from a representative experiment are reported. Experimental conditions were repeated in triplicate or quadruplicate, and glucose uptakes were measured and reported as nanomoles per $10 \mathrm{~min}$ per well \pm standard error. A two-tailed paired $t$ test was used to show statistical significance. Each experiment had a 30-min treatment phase followed by a 10-min glucose uptake phase. In one experiment, to determine if verapamil was required to be present in order to inhibit activation of glucose uptake, L929 fibroblast cells were exposed to $150 \mu \mathrm{M}$ verapamil, the minimum concentration that completely inhibited activation, only during a 60 -min time period just prior to the 30 -min treatment phase, or only during the 30-min treatment phase, or only during the 10-min glucose uptake phase.

To initiate each experiment, approximately $1.2 \times 10^{5}$ L929 fibroblast cells were plated into each well of a 24-well culture-treated plate in $1.0 \mathrm{~mL}$ of low glucose $(5.5 \mathrm{mM})$ Dulbecco's modified Eagle medium (DMEM) supplemented with $10 \%$ fetal bovine serum and $1 \%$ penicillin/streptomycin. The cells were grown overnight at $37^{\circ} \mathrm{C}$ in an incubator supplied with humidified room air with $5 \% \mathrm{CO}_{2}$. The next day, the cells were rinsed with $0.2 \mathrm{~mL}$ of treatment media and then incubated in $0.8 \mathrm{~mL}$ of fresh treatment media for the $30 \mathrm{~min}$ at $37^{\circ} \mathrm{C}$. For investigating the effects of verapamil under basal conditions, the treatment media consisted of lowglucose DMEM containing 0, 50, 150, or $300 \mu \mathrm{M}$ verapamil. For exploring the effects of verapamil on the ability to activate GLUT1 by the glucose deprivation, the treatment media consisted of glucose-free DMEM with $0,50,150$, or $300 \mu \mathrm{M}$ verapamil. To determine if calcium ion concentrations play a role in the effects of verapamil, the treatment media consisted of glucose-free DMEM supplemented with the effective inhibitory concentration of verapamil $(150 \mu \mathrm{M})$ plus either $5.0 \mathrm{mM} \mathrm{CaCl} 2$ to enhance calcium levels or $4.0 \mathrm{mM}$ EDTA to lower calcium levels. 
Glucose uptake was then measured using radiolabeled 2deoxyglucose (2-DG) [23]. The media was replaced with $0.3 \mathrm{~mL}$ of glucose-free HEPES buffer $(140 \mathrm{mM} \mathrm{NaCl}$, $5 \mathrm{mM} \mathrm{KCl}, 20 \mathrm{mM}$ HEPES/Na, $\mathrm{pH}=7.4,2.5 \mathrm{mM} \mathrm{MgSO}_{4}$, $1 \mathrm{mM} \mathrm{CaCl}_{2}, 2 \mathrm{mM} \mathrm{NaPyr}, 1 \mathrm{mM}$ mannitol) containing the same concentrations of verapamil, $\mathrm{CaCl}_{2}$, or EDTA that were present in the treatment phase unless indicated differently. This buffer was supplemented with $1.0 \mathrm{mM}$ $(0.3 \mu \mathrm{Ci} / \mathrm{mL}) 2-\mathrm{DG}\left(1,2-{ }^{3} \mathrm{H}\right)$ and $1.0 \mathrm{mM}(0.02 \mu \mathrm{Ci} / \mathrm{mL})$ mannitol $\left(1-{ }^{14} \mathrm{C}\right)$. After 10 -min incubation, cells were briefly rinsed three times with cold glucose-free HEPES to terminate uptake and remove excess radioactivity. The cells were lysed by gentle shaking in $0.5 \mathrm{~mL}$ lyses buffer (10 mM Tris, $\mathrm{pH}=7.4,150 \mathrm{mM} \mathrm{NaCl}, 5 \mathrm{mM}$ EDTA, $1.0 \%$ triton X-100, 0.4\% SDS). Cell contents were then completely digested by adjusting the solution to $0.5 \mathrm{M} \mathrm{NaOH}$. The mixture was then added to scintillation vials with $3.0 \mathrm{~mL}$ of Beckman Ready-Safe liquid scintillation cocktail. The ${ }^{3} \mathrm{H}$ and ${ }^{14} \mathrm{C}$ radioactivity was measured using a Beckman LS 6500 liquid scintillation counter. Glucose uptake was determined from the amount of ${ }^{3} \mathrm{H}-2-\mathrm{DG}$ radioactivity isolated with the cells after subtracting out the extracellular ${ }^{3} \mathrm{H}-2-\mathrm{DG}$. The extracellular ${ }^{3} \mathrm{H}-2-\mathrm{DG}$ was determined from the amount of ${ }^{14} \mathrm{C}$ mannitol (not transported in these cells) that was also isolated with the cells $[22,23,28]$.

\section{Results}

Verapamil inhibited glucose uptake in a dose-dependent manner under basal conditions reaching a statistically significant reduction of over $50 \%$ at $300 \mu \mathrm{M}$ verapamil (reduction from $0.58 \pm 0.056$ to $0.26 \pm 0.029 \mathrm{nmol} 10 \mathrm{~min}^{-1}$ well $^{-1}$; see Fig. 1). Verapamil had a more dramatic inhibitory affect on the activation of glucose transport by glucose deprivation. Glucose deprivation of $30 \mathrm{~min}$ activated 2-DG uptake $322 \%$, increasing it from $0.58 \pm 0.056$ to $1.87 \pm 0.089 \mathrm{nmol} 10 \mathrm{~min}^{-1} \mathrm{well}^{-1}$, but this activation was inhibited by verapamil in a dose-dependent manner (see Fig. 2). Complete inhibition of activation was achieved in this experiment by $150 \mu \mathrm{M}$ verapamil $(0.49 \pm 0.028 \mathrm{com}$ pare to basal uptake of $0.58 \pm 0.056 \mathrm{nmol} 10 \mathrm{~min}^{-1} \mathrm{well}^{-1}$ ). Given the calcium channel blocking activity of verapamil, we were curious to know if this inhibition of glucose activation could be attributed to changes in calcium ion concentrations. We investigated this indirectly by measuring the effects of either adding $5.0 \mathrm{mM} \mathrm{CaCl}_{2}$ to increase calcium ion concentrations or $4.0 \mathrm{mM}$ EDTA to lower them. Neither of these agents alone significantly altered the ability to stimulate L929 cells by glucose deprivation (data not shown). In order to determine if altering calcium ion concentrations using these agents altered verapamil's inhibitory effects on the activation of glucose uptake, glucose uptake was measured in L929 cells after a 30-min exposure to glucose-free media with $150 \mu \mathrm{M}$ verapamil alone (a concentration which previously was shown to completely inhibit activation of glucose uptake (see Fig. 2)) and in combination with either $5.0 \mathrm{mM} \mathrm{CaCl}_{2}$ or $4.0 \mathrm{mM}$ EDTA. The data are shown in Fig. 3 and are expressed as a percent of stimulation, which was calculated by subtracting basal glucose uptake from the activated uptake. The results of this experiment indicate that $150 \mu \mathrm{M}$ verapamil reduced stimulation to $42.2 \%$ of maximum stimulation and that the addition of $\mathrm{Ca}^{+2}$ or EDTA had no additional effect (41.4\% and $40.8 \%$, respectively). It should be noted that the inhibition of activation by $150 \mu \mathrm{M}$ verapamil reported in this experiment (about $60 \%$ inhibition) was not as extensive as was reported in the dose-dependent experiment shown in Fig. 2 (about 100\% inhibition). This range of inhibitory values can be attributed to differences is cell density that occur from one experiment to the next.

To determine if verapamil was required to be present to inhibit activation, L929 cells were exposed to $150 \mu \mathrm{M}$ verapamil either only during a 60 -min pre-activation period, or only during the 30-min glucose deprivation activation period, or only during the 10-min glucose uptake period. As seen from the data in Table 1, only exposure to verapamil during the activation phase significantly inhibited activated glucose uptake. Exposure to verapamil only during the 10min uptake tended to reduce uptake, but it was not statistically significant. It should be noted that the degree of inhibition by verapamil when present only during the activation period was not as great as when it was included in both the activation and uptake periods, approximately a $40 \%$ reduction (Table 1) compared to a $60 \%$ (Fig. 3).

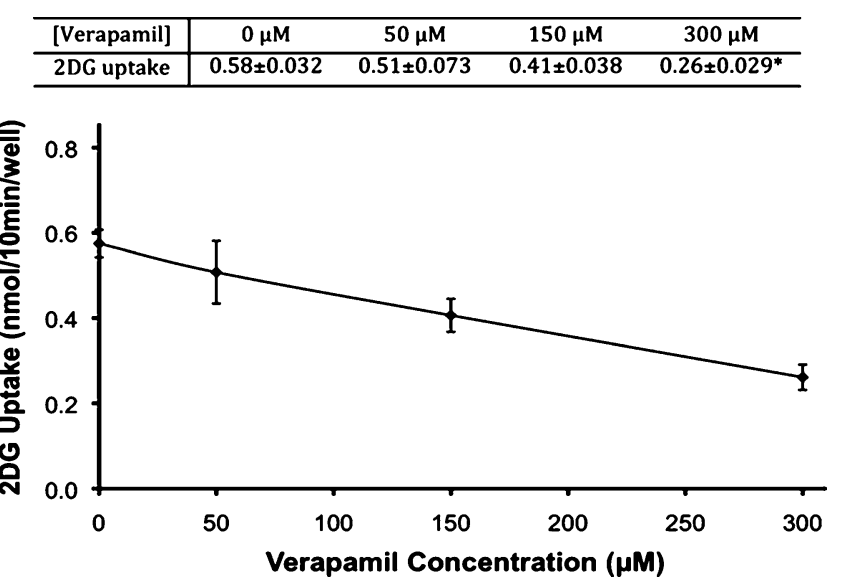

Fig. 1 Effects of verapamil on basal 2-DG uptake in L929 fibroblast cells. Cells were incubated at $37^{\circ} \mathrm{C}$ for $30 \mathrm{~min}$ in low-glucose DMEM supplemented with $0,50,150$, or $300 \mu \mathrm{M}$ verapamil as indicated. Tenminute 2-DG uptakes were then measured. Data values are displayed on top as means $\pm \mathrm{SE}$ for three samples from a representative experiment. Significantly lower than control at $* P=0.014$ 


\begin{tabular}{l|cccc}
\hline [Verapamil] & $0 \mu \mathrm{M}$ & $50 \mu \mathrm{M}$ & $150 \mu \mathrm{M}$ & $300 \mu \mathrm{M}$ \\
\hline 2DG uptake & $1.87 \pm 0.051$ & $1.03 \pm 0.037^{*}$ & $0.49 \pm 0.016^{*}$ & $0.22 \pm 0.052^{*}$ \\
\hline
\end{tabular}

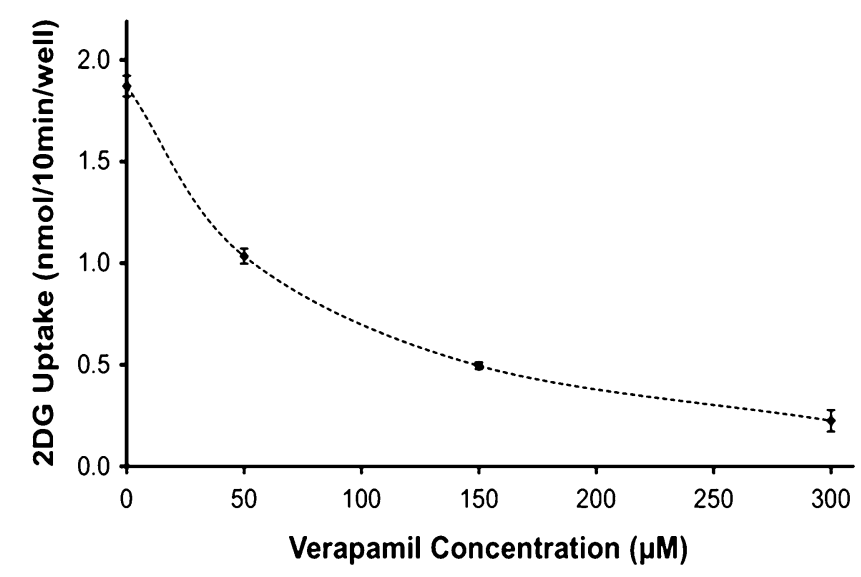

Fig. 2 Effects of verapamil on activated 2-DG uptake in L929 fibroblast cells. Cells were incubated at $37^{\circ} \mathrm{C}$ for $30 \mathrm{~min}$ in glucosefree DMEM supplemented with $0,50,150$, or $300 \mu \mathrm{M}$ verapamil as indicated. Ten-minute 2-DG uptakes were then measured. Data values are displayed on top as means $\pm \mathrm{SE}$ for samples of a representative experiment. Significantly lower than control at $* P<0.01$

\section{Discussion}

Previous studies demonstrate that verapamil inhibits glucose uptake in insulin-sensitive tissues such as adipocytes skeletal myocytes and cardiac myocytes [3, 9, 26-28]. The mecha-

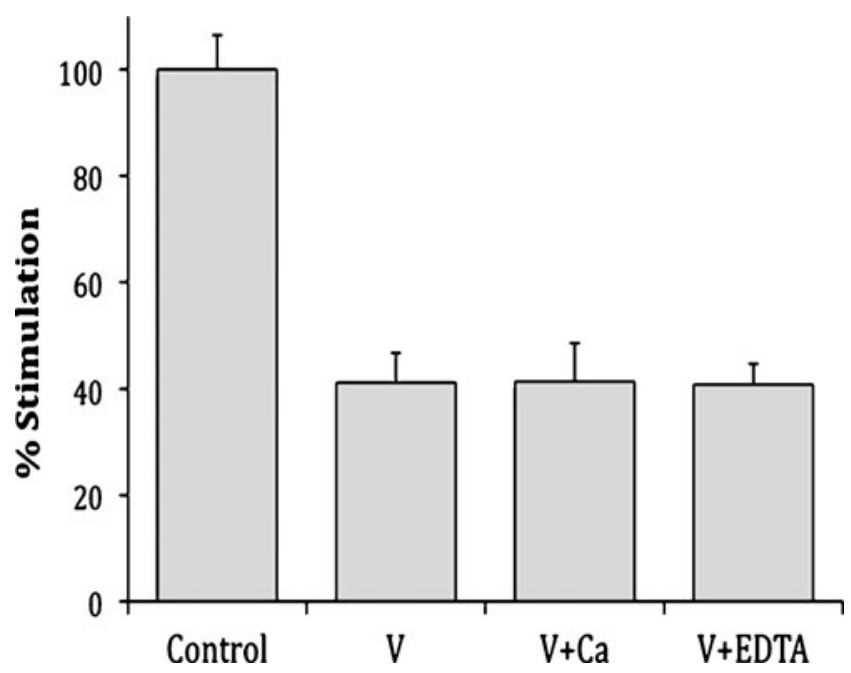

Fig. 3 Effects of $\mathrm{Ca}^{+2}$ and EDTA on the verapamil-inhibition of activation of glucose uptake by glucose deprivation. L929 fibroblast cells were incubated at $37^{\circ} \mathrm{C}$ for $30 \mathrm{~min}$ in glucose-free DMEM buffer with no additions (Control), $150 \mu \mathrm{M}$ verapamil $(V), 150 \mu \mathrm{M}$ verapamil plus $5.0 \mathrm{mM} \mathrm{Ca}^{+2}(V+C a)$, or $150 \mu \mathrm{M}$ verapamil plus $4.0 \mathrm{mM}$ EDTA $(V+E D T A)$. Ten-minute 2-DG uptakes were then measured. Data are means \pm SE for four samples of a representative experiment and expressed as a percentage of the stimulated uptake. All three verapamil conditions statistically decreased 2-DG uptake $(P<0.01)$, but added $\mathrm{Ca}^{+2}$ or EDTA had no additional effect
Table 1 Effects of verapamil added at different times on 2-DG uptake in L929 fibroblast cells

\begin{tabular}{lc}
\hline Experimental condition & $\begin{array}{l}\text { 2DG uptake } \\
\left(\mathrm{nmol} 10 \mathrm{~min}^{-1} \mathrm{well}^{-1}\right)\end{array}$ \\
\hline Basal uptake (low-glucose media) & $0.80 \pm 0.004$ \\
Activated uptake (no-glucose media) & $4.21 \pm 0.112$ \\
Verapamil $(150 \mu \mathrm{M})$ in pre-activation only & $4.05 \pm 0.123$ \\
Verapamil $(150 \mu \mathrm{M})$ in activation only & $2.92 \pm 0.091^{*}$ \\
Verapamil $(150 \mu \mathrm{M})$ in uptake only & $3.92 \pm 0.162$ \\
\hline
\end{tabular}

Cells were incubated in a 60 -min pre-activation period at $37^{\circ} \mathrm{C}$ low-glucose DMEM buffer. No-glucose media were then added in a 30-min activation period (except basal cells which received fresh low-glucose media) followed by a 10 -min 2-DG uptake period as described in "Methods"; $150 \mu \mathrm{M}$ verapamil was included only in the pre-activation, activation, or uptake period as indicated. Data are means \pm SE for three wells of a representative experiment

$* P<0.01$, significantly lower than activated uptake

nism of this inhibition is largely unknown, but a recent study in 3 T3 adipocytes suggested that verapamil inhibits the phosphorylation and activation of Akt, a downstream mediator of the insulin-dependent PI3K signaling system [3]. Others have suggested a more direct inhibition of the GLUT transporters [28, 29]. However, the effects of verapamil could not be assigned to a particular GLUT transporter, since the cells used in all these studies expressed multiple transporters. By using L929 fibroblast cells - a cell line expresses only GLUT1 [32]—-we were able to investigate the effects of verapamil on the transport activity of only the GLUT1 transporters. The effects of verapamil on cells containing only GLUT1 have not been reported. This transporter is expressed in a wide variety of tissues and is largely responsible for a basal level of glucose uptake. In muscle tissue, a tissue that is largely responsible of whole body glucose clearance, $25-40 \%$ of the transporters under non-insulin conditions are GLUT1 [30, 31]. In addition, there is accumulating evidence indicating that activity of GLUT1 can be acutely activated by cell stress. Studies in cells that express GLUT1 reveal that short-term exposure to cell stressors such as hypoxia, hyperosmolarity, respiration inhibitors, and glucose deprivation all activate glucose uptake [21-25]. The data reported here reveal for the first time that verapamil inhibits the glucose transport activity of GLUT1 in a dose-dependent manner. The effects of verapamil on basal glucose uptake are modest and reach significance only at $300 \mu \mathrm{M}$ verapamil. Previous work in striated muscles has reported that concentrations of verapamil up to $200 \mu \mathrm{M}$ did not affect basal glucose [28]. This is not inconsistent with our observations. However, much more dramatic are the effects of verapamil on the activation of GLUT1 by cell stress (glucose deprivation). Activation of 
the transporter is completely inhibited by $150 \mu \mathrm{M}$ verapamil (Fig. 2). This effect does not appear to be dependent of the drug's calcium channel blocking properties, since adding agents that would be expected to change concentrations of calcium ions ( $5 \mathrm{mM} \mathrm{CaCl}_{2}$ or $4 \mathrm{mM}$ EDTA) did not alter the inhibitory effects of verapamil (Fig. 3). Inhibition of GLUT1 activity may be an important contributor to the toxic effects of CCB. In addition to inhibiting insulin-sensitive glucose uptake as noted in previous studies, CCBs may also both inhibit GLUT1 as well as prevent the activation of this transporter that normally occurs under stress. Given the observed hyperglycemia that accompanies CCB toxicity, the cellular stress provided in these studies, glucose deprivation, is likely not the cellular stress expected. Nevertheless, given that there are multiple stressors that activate GLUT1 and it is not unreasonable to expect that in a CCB toxic event, cells would experience stress and CCBs may prevent the normal activation of this transporter. Interestingly, verapamil had to be present during the activation phase (glucose deprivation) to be inhibitory. A pre-incubation and removal of verapamil did not prevent the activation of glucose uptake (see Table 1). This suggests a direct interaction of verapamil with a component of the activation process. However, that interaction may not be with the GLUT1 protein itself, since incubation with verapamil only during the uptake period did not prevent the activation of transport by glucose deprivation (Table 1). This matches results from a previous study, which reported that the transport activity of GLUT1 reconstituted in liposomes was not inhibited by verapamil [33].

The detailed mechanism of the activation of GLUT1 is currently unknown. However, there are two plausible final steps in the activation process that have been proposed. Rubin and Ismail-Beigi have proposed that activation of glucose uptake by cell stress triggers a movement of GLUT1 to lipid rafts where the change in lipid environment activates the transporter [24]. On the other hand, Carruthers has suggested that the activation of GLUT1 in erythrocytes is triggered by a formation of tetramers [34]. Our data suggest that verapamil interferes primarily with the activation process rather than with the transporter itself, but the details are not yet delineated.

\section{Conclusion}

This study reveals the unique finding that verapamil in a dose-dependent manner has an inhibitory effect on both the basal activity and the stress-activated transport activity of GLUT1. The inhibition of GLUT1 may be a contributing factor to the hyperglycemia observed in $\mathrm{CCB}$ poisoning.

Acknowledgment Special thanks to Dr. Laura Bechtel for her review and critique of the manuscript.

\section{References}

1. Bronstein AC, Spyker DA, Cantilena LR Jr, Green JL, Rumack BH, Heard SE (2008) Annual Report of the American Association of Poison Control Centers' National Poison Data System (NPDS): 25th Annual Report. Clin Toxicol (Phila) 46(10):927-1057

2. Litovitz TL, Felberg L, White S, Klein-Schwartz W (1996) 1995 Annual Report of the American Association of Poison Control Centers Toxic Exposure Surveillance System. Am J Emerg Med 14(5):487-537

3. Bechtel LK, Haverstick DM, Holstege CP (2008) Verapamil toxicity dysregulates the phosphatidylinositol 3-kinase pathway. Acad Emerg Med 15(4):368-374

4. Boyer EW, Duic PA, Evans A (2002) Hyperinsulinemia/euglycemia therapy for calcium channel blocker poisoning. Pediatr Emerg Care 18(1):36-37

5. DeWitt CR, Waksman JC (2004) Pharmacology, pathophysiology and management of calcium channel blocker and beta-blocker toxicity. Toxic Rev 23(4):223-238

6. Holstege C, Kirk M, Furbee R, Wermuth M (1998) Wide complex dysrhythmia in calcium channel blocker overdose responsive to sodium bicarbonate. J Toxicol Clin Toxicol 36(5):509

7. Ohta M, Nelson J, Nelson D, Meglasson MD, Erecinska M (1993) Effect of $\mathrm{Ca}++$ channel blockers on energy level and stimulated insulin secretion in isolated rat islets of Langerhans. J Pharmacol Exp Ther 264(1):35-40

8. Tanen DA, Ruha AM, Curry SC, Graeme KA, Reagan CG (2000) Hypertonic sodium bicarbonate is effective in the acute management of verapamil toxicity in a swine model. Ann Emerg Med 36 (6):547-553

9. TenHarmsel A, Holstege CP, Louters LL (2005) High dose insulin reverses verapamil inhibition of glucose uptake in mouse striated muscle (abstract). Ann Emerg Med 46:S77

10. Kline JA, Raymond RM, Schroeder JD, Watts JA (1997) The diabetogenic effects of acute verapamil poisoning. Toxicol Appl Pharmacol 145(2):357-362

11. Holstege CP, Dobmeier S (2005) Cardiovascular challenges in toxicology. Emerg Med Clin North Am 23(4):1195-1217

12. Kline JA, Leonova E, Williams TC, Schroeder JD, Watts JA (1996) Myocardial metabolism during graded intraportal verapamil infusion in awake dogs. J Cardiovasc Pharmacol 27(5):719726

13. Levine M, Boyer EW, Pozner CN, Geib AJ, Thomsen T, Mick N, Thomas SH (2007) Assessment of hyperglycemia afte calcium channel blocker overdoses involving diltiazem or verapamil. Crit Care Med 35(9):2071-2075

14. Holstege CP, Eldridge DL, Rowden AK (2006) ECG manifestations: the poisoned patient. Emerg Med Clin North Am 24 (1):159-177, vii

15. Lheureux PE, Zahir S, Gris M, Derrey AS, Penaloza A (2006) Bench-to-bedside review: hyperinsulinaemia/euglycaemia therapy in the management of overdose of calcium-channel blockers. Crit Care 10(3):212

16. Yuan TH, Kerns WP 2nd, Tomaszewski CA, Ford MD, Kline JA (1999) Insulin-glucose as adjunctive therapy for severe calcium channel antagonist poisoning. J Toxicol Clin Toxicol 37(4):463-474

17. (2005) Toxicology in ECC. Circulation 112(24 (Suppl I)):126132

18. (2005) Pediatric advanced life support. Circulation 112(24(Suppl I)):167-187

19. Zhao FQ, Keating AF (2007) Functional properties and genomics of glucose transporters. Current Genomics 8(2):113-128

20. Baldwin SA, Barros LF, Griffiths M et al (1997) Regulation of GLUT1 in response to cellular stress. Biochem Soc Trans 25 (3):954-958 
21. Barnes K, Ingram JC, Porras OH et al (2002) Activation of GLUT1 by metabolic and osmotic stress: potential involvement of AMP-activated protein kinase (AMPK). J Cell Sci $115(\mathrm{Pt}$ 11):2433-2442

22. Louters LL, Dyste SG, Frieswyk D et al (2006) Methylene blue stimulates 2-deoxyglucose uptake in L929 fibroblast cells. Life Sci 78(6):586-591

23. Roelofs B, Tidball A, Lindborg AE, TenHarmsel A, Vander Kooy TO, Louters LL (2006) Acute activation of glucose uptake by glucose deprivation in L929 fibroblast cells. Biochimie 88 (12):1941-1946

24. Rubin D, Ismail-Beigi F (2003) Distribution of Glut1 in detergentresistant membranes (DRMs) and non-DRM domains: effect of treatment with azide. Am J Physiol Cell Physiol 285(2):C377-383

25. Shetty M, Loeb JN, Vikstrom K, Ismail-Beigi F (1993) Rapid activation of GLUT-1 glucose transporter following inhibition of oxidative phosphorylation in clone 9 cells. J Biol Chem 268 (23): 17225-17232

26. Khil LY, Cheon AJ, Chang TS, Moon CK (1997) Effects of calcium on brazilin-induced glucose transport in isolated rat epididymal adipocytes. Biochem Pharmacol 54(1):97-101

27. Whitehead JP, Molero JC, Clark S, Martin S, Meneilly G, James DE (2001) The role of $\mathrm{Ca} 2+$ in insulin-stimulated glucose transport in 3T3-L1 cells. J Biol Chem 276(30):27816-27824
28. Cartee GD, Briggs-Tung C, Holloszy JO (1992) Diverse effects of calcium channel blockers on skeletal muscle glucose transport. Am J Physiol 263(1 Pt 2):R70-75

29. Ardizzone TD, Lu XH, Dwyer DS (2002) Calcium-independent inhibition of glucose transport in PC-12 and L6 cells by calcium channel antagonists. Am J Physiol Cell Physiol 283(2):C579-586

30. Marette A, Richardson JM, Ramlal T, Balon TW, Vranic M, Pessin JE, Klip A (1992) Abundance, localization, and insulininduced translocation of glucose transporters in red and white muscle. Am J Physiol Cell Physiol 263(2PT1):C443-452

31. Piper RC, Hess LJ, James DE (1992) Differential sorting of two glucose transporters expressed in insulin-sensitive cells. Am J Physiol Cell Physiol 260(3Pt1):C570-580

32. Liong E, Kong SK, Au KK et al (1999) Inhibition of glucose uptake and suppression of glucose transporter 1 mRNA expression in L929 cells by tumour necrosis factor-alpha. Life Sci 65 (15):PL215-220

33. Wheeler TJ, Cole D, Hauck MA (1998) Characterization of glucose transport activity reconstituted from heart and other tissues. Biochim Biophys Acta 1414(1-2):217-230

34. Herbert DN, Carruthers A (1992) Glucose transporter oligomeric structure determines transport function: reversible redoxdependent interconversion of tetrameric and dimeric GLUT1. J Biol Chem 267(33):23829-23838 